\title{
Implementing new production management modes - Orchestration of simultaneous improvement activities
}

\author{
J. O. Riis, J. Knopp \\ Dept. of Production, Aalborg University, Fibigerstraede 16, \\ DK-9220 Aalborg, Denmark \\ E-mail: i9jor@iprod.auc.dk i9jk@iprod.auc.dk
}

\begin{abstract}
This paper represents an attempt to shed light on an important issue for development of production management, namely the orchestration of several individual development projects and initiatives of different type and nature necessary for achieving an overall significant improved performance.

The paper will first introduce three types of development initiatives: (1) Crossfunctional development; (2) Functional development; and (3) Local development. Then incremental and innovative changes will be discussed and a more differentiated classification will be proposed. This provides a framework for modeling different development processes which will be illustrated by means of two case examples. In addition, the results of a Danish survey on Continuous Improvements will be related to the three types of initiatives. Tentative theoretical and practical implications will be outlined.
\end{abstract}

\section{Keywords}

Implementation of production management. Multi-project management. Continuous Improvement. 


\section{INTRODUCTION}

Much research on production management is void of any consideration of how the developed theory, method or system should be implemented in practice. This may often be justified in view of the requirements and context in which much research is carried out. However, if we want to bridge the gap between theory and practice, we need to address the implementation process, in the first place to understand its nature and secondly to derive approaches for speedy introduction and adoption of new production management modes.

The Japanese effort to combine Kaizen with any technical change whether it be within quality, productivity, maintenance, or just-in-time, is a clear indication of the acceptance of the importance of implementation issues, cf. Imai (1986), Suzaki (1993). An essential element of Kaizen is the involvement of employees in the process of improvement which increasingly has been seen as a major challenge in Western industrial countries. In the U.S. the concept of empowerment has appeared as an important issue, and in Western Europe the notion of Continuous Improvement has gained wide-spread recognition, cf. Bessant et al (1995).

However, there has been a tendency to view Continuous Improvements as closely related to changes within a working group. Production Management, in contrast, focuses heavily on improving the overall interplay between planning units and working groups. Hence, there is a need for linking improvements at various levels in the industrial enterprise.

Based on empirical studies, we have observed that changing production management often requires changes in other elements of a production system, such as production processes, wage systems, product program, purchase, etc. To illustrate, in one industrial enterprise a needed change of the production management system came to a halt after a good start, because of the wage system. Its incentives did not at all stimulate any changes in the current operations. Hence, focus had to be drawn to adjusting the wage system. Thus, when addressing implementation of production management, it is necessary to adopt a broader contextual view.

At any point in time, an industrial enterprise will carry out several individual improvement initiatives aimed at various parts of a production system and often with different time horizons. The orchestration of such projects represents a major challenge.

In this paper we shall present a model of a development and implementation process which captures the complex picture of many, different types of individual development initiatives concurrently in progress in an industrial enterprise.

Secondly, based on empirical case examples the paper draws implications for planning the implementation process for improving production management in an industrial enterprise. 


\section{THREE TYPES OF COMPANY DEVELOPMENT}

Based on observations in several industrial enterprises, we have noticed that most often a company development process involves activities of different nature. This has led us to identify three different types of focal points for company development.

\subsection{Cross-functional and interdepartmental development}

This type of development looks at the overall organization and the interaction between subsystems (e.g. departments, sections and units). It addresses the need for overall integration of activities, e.g. derived from customer demands. Ordinarily, the role of the various management systems is to take care of this task, such as the production planning and control system, quality management system, economic control system, etc.

In production management the Materials Requirement Planning (MRP) and Optimized Production Technique (OPT) represent two approaches to planning and control of the production flow, focusing respectively on the acquisition of materials and on bottlenecks. By suggesting the preparation of a Problem Matrix through a collaborative process and development of a Production Management Concept we have provided means for diagnosing the complex interplay between sections and departments in connection with production planning and for establishing an overall picture of how the interplay should be (Riis, 1990).

\subsection{Functional development}

This type of development focuses on the development in one of the functional areas, such as product development, production engineering, personnel and administrative systems development. It addresses the need for differentiation and specialization.

In any organization it is necessary to develop competencies in a number of areas capable of establishing effective support systems, such as management systems for production planning, quality, finance, wage system, personnel training and development, etc. Similarly, professional expertise is needed for developing the company's products and services and the production and logistics systems required for realizing the delivery of products and services to customers.

Often these functions take part in the daily operation. However, their main role in the enterprise is to develop improved solutions for the daily operation. 


\subsection{Local development}

This type of development is concerned with the individual organizational unit responsible for a certain part of the daily operation, e.g. a production group or a workshop. As we have seen, especially under the umbrella of Continuous Improvement, such an organizational unit is often capable of not only carrying out the daily operation, but also of suggesting and implementing significant improvements. Local development is often seen as a means for employee development and for stimulating creativity in operations.

The formation of production groups, e.g. on the basis of production flow analyses and the application of group technological principles, has made it easier to define the task (job) of the group and to identify appropriate decision variables within the group.

Although we are primarily focusing on the operational activities, represented by a production group, an assembly group, or an administrative unit responsible for invoicing, local development may also take place in an engineering design group when they adopt a new method or computer software which may improve their own performance. For instance, Quality Circles have successfully been implemented in these areas in Japan.

\subsection{Interconnections between the three types of development}

As demonstrated above, we believe that it is possible to distinguish between the three types of development in the sense that any development effort in an enterprise may be categorized as either of the three types. However, this is not to say that they are independent. To the contrary, a great many different interdependencies exist, the understanding of which represent a challenge to both theory and practice. To illustrate we shall give a few examples of such interdependencies.

The definition of the local organizational unit. Several production management systems implicitly consider a single machining tool or machining center as a planning unit and frequently insert an inventory between two units. As a consequence, a plant is often divided into a large number of planning units, typically between $50-100$.

By introducing larger organizational units, e.g. a production or an assembly group, with the task of completing the operations or assembly of a part or component, the plant may be divided into fewer planning units, typically $8-12$. Not only is more autonomy given to each unit, but the overall planning task becomes much easier and provides a better opportunity to maintain a comprehensive understanding of the overall planning situation.

Hence, the definition of local organizational units has a great influence on the ability to establish an overview at a cross-functional level. Development of a 
production management concept with a rather small number of planning units, and a joint cross-functional and local development holds great potential for synergy.

The recent focus on activity chains and business processes may similarly lead to formation of technical-administrative groups (planning units) situated along a business activity chain providing a basis for significant improvements of both local and cross-functional development type.

Integrating functional development. As has been observed in Continuous Improvement activities, at a certain stage continued local development will depend on support from one or more functional developments, e.g. an improvement of the wage system (e.g. a shift in the bonus system), of the quality management system, or of the production planning system. The effort on integration in manufacturing in the past decade has clearly demonstrated that suboptimization is likely, if not the effort of the various functions are coordinated. Furthermore, an integrated effort has great potential for yielding a significant synergy with a multiplying effect on the overall performance.

Hence, the extent to which functional developments are coordinated will have a marked influence on cross-functional and local development.

\section{INCREMENTAL OR INNOVATIVE DEVELOPMENT}

The development effort within each type may traditionally be categorized as either incremental or innovative, cf. Imai 1986. For cross-functional development, the OPT approach to production planning and control with its focus on bottlenecks has proved to be very successful as an incremental cross-functional change. We have been involved in several practical cases in which it was possible with a rather limited effort to identify critical bottlenecks and furthermore quickly to initiate a drastic change in the overall performance of the production system.

On the other hand, the implementation of a Just-in-Time mode of production implies a shift in paradigm, requiring a change in attitudes, a new management system, etc. This signifies an innovative development. In a similar manner, it is possible to distinguish between incremental and innovative development of the functional and local type.

However, there is a need to differentiate between the nature of the change and the pace at which it is implemented. The nature of change may either be incremental or radical. An incremental change rests on the current mode of operation and its systems and seeks improvements within this framework. On the other hand, a radical change implies a shift of paradigm, i.e. a new point of departure based on a different approach or set of assumptions.

The other dimension captures the pace of realizing a change which may either be a sudden, fast and discontinuous change, or the change may be gradually implemented over a longer period of time. By combining the two dimensions we 
obtain four options, as shown below in figure 1. They reflect a more differentiated view of the nature and pace of the development process.

\begin{tabular}{|c|c|c|}
\hline Nature of Change & $\begin{array}{l}\text { Pace of } \\
\text { Sudden and } \\
\text { fast }\end{array}$ & $\begin{array}{l}\text { Change } \\
\text { Gradual and } \\
\text { slow }\end{array}$ \\
\hline $\begin{array}{l}\text { Incremental } \\
\text { (resting on current mode } \\
\text { of operation) }\end{array}$ & $\begin{array}{l}\text { Crash or crisis } \\
\text { program }\end{array}$ & $\begin{array}{l}\text { Continuous } \\
\text { improvement }\end{array}$ \\
\hline $\begin{array}{l}\text { Radical } \\
\text { (based on a new paradigm) }\end{array}$ & Big Leap & $\begin{array}{l}\text { Innovative } \\
\text { improvement }\end{array}$ \\
\hline
\end{tabular}

Figure 1 Four modes of development dependent on the nature and pace of change

\section{MODELING A DEVELOPMENT PROCESS: TWO CASE EXAMPLES}

With the three types of development and four modes of change (nature and pace) we have a set of descriptors for modeling a development process, as a step towards understanding the nature of an overall development process and for planning. We shall demonstrate some of the aspects of modeling by means of two case examples.

\section{Case A}

With the intention of developing a new way for the sales offices abroad to interact with the domestic production plant aimed at speeding the handling of custom designed products, the management initiated three parallel development processes: (1) an analysis and diagnosis of the activity chains associated with handling of custom orders across functions, which initiated local development activities; (2) a systems design project aimed at developing a new computerized logistics management system; and (3) the development of a vision of the future company, especially capturing the logistics aspects.

The development process of the project is depicted in figure 2 .

As mentioned, the incremental process initiated at the cross-functional level started a continuous improvement process in several production units. However, after some time the local development process came to a halt. Originally, management believed that the local development processes would lead to the development of an overall vision; but this did not take place. One reason offered was the inadequate background of the operators and foremen to actively take part in an innovative 
discussion at the cross-functional level. Instead, management and external consultants developed a vision and put much effort into conveying the vision to the employees.

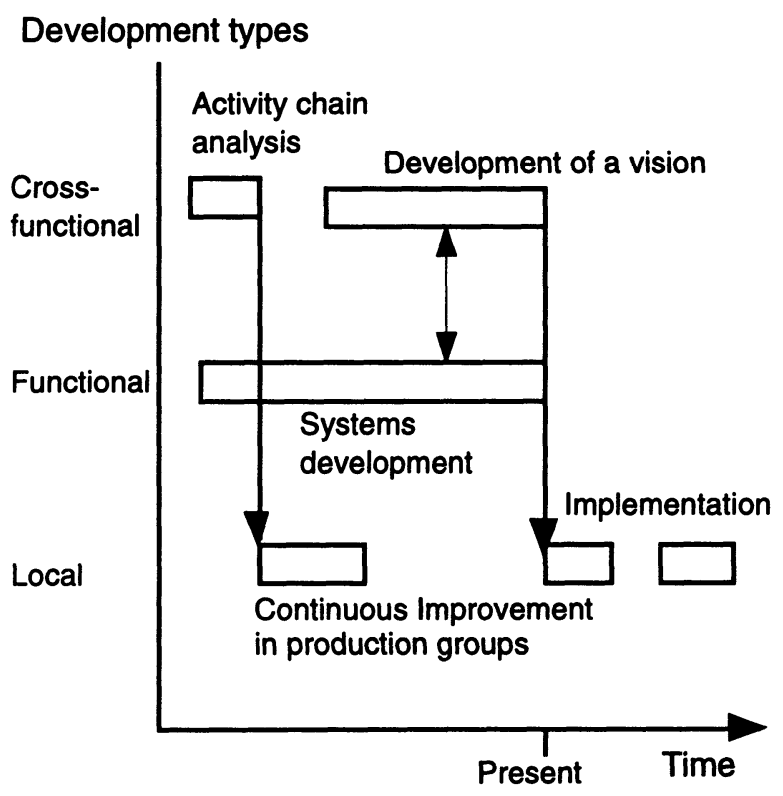

Figure 2 The development process in case A

Another observation relates to the cross-functional and functional development. Because management in the middle of the process took over the responsibility for the development of a vision from the production manager, it realized that this process ought to be coordinated with the systems design project which it was also responsible for. Hence, more or less by accident the two development types became coordinated with mutual benefit.

At this point management realized that the local development had stopped and noticed that the workers' perception of the necessity to improve the logistic performance was very much different from what management had perceived. As a way of establishing a connection to local development, management arranged a study tour for all employees to the annual European exhibition of its industry which would also include an opportunity to see competitors' products. This brought about a shift in the employees' perceived need to change.

The case example clearly demonstrates the interrelationship between the three different types of development. Management has learned that it is necessary to include all three types in the overall planning of improvement initiatives. 


\section{Case B}

In an attempt to gain a better overview of its many development activities, the cross-functional section of company B analyzed 11 completed and 7 newly started development projects which resulted in the map shown in figure 3.

The mapping was carried out collaboratively between engineers from the crossfunctional section and researchers and demonstrated that it was, in fact, possible to identify a project as one of the three types of development. However, it was useful to think of the person who is carrying out the activity, rather than those who will be impacted. Furthermore, it was suggested in some instances to split a larger project into sub-projects, because they belonged to different development types. As to the distinction between incremental and innovative, it was fairly easy to identify incremental initiatives, whereas it was rather difficult to arrive at a clear definition of innovative development. However, the discussion initiated the distinction between nature and pace of change, as introduced in section 3 of this paper.

Only major relationships between development projects are shown in figure 3. However, the analysis gave rise to a discussion of why some projects apparently stood alone. Several types of relationships were defined and will be used in further analysis.

The mapping also led to identification of different modes of managing company development initiatives. One mode is similar to the traditional Kaizen activities predominantly of local nature, and it was noted that the projects in figure 3 are strongly biased towards cross-functional activities compared to the overall company picture with the relatively few local development activities. Another mode is functional development projects which tend to remain as such, despite many crossfunctional and local development elements. And a third mode is a traditional development program which would start with a broad feasibility study as a crossfunctional activity. If a continuation is warranted, several projects would be initiated of all three types of development.

The analysis gave rise to the following conclusions:

- A development project on logistics was defined as an EDP project (functional development). This explained some of the difficulties encountered. If initially the project had been defined as also related to cross-functional and local development, management felt that it would have been implemented much faster.

- There were many stand-alone projects. If they had been related to other improvement activities, management felt that a larger synergy would have emerged.

- The large number of improvement projects gave rise to a critical assessment of the capacity and capability to also implement the initiated projects.

- Management realized that it was necessary to develop a set of different working modes for managing improvement activities which would include a mixture of the three types of development and a more systematic discussion of when to adopt an incremental and a radical scope of change. 


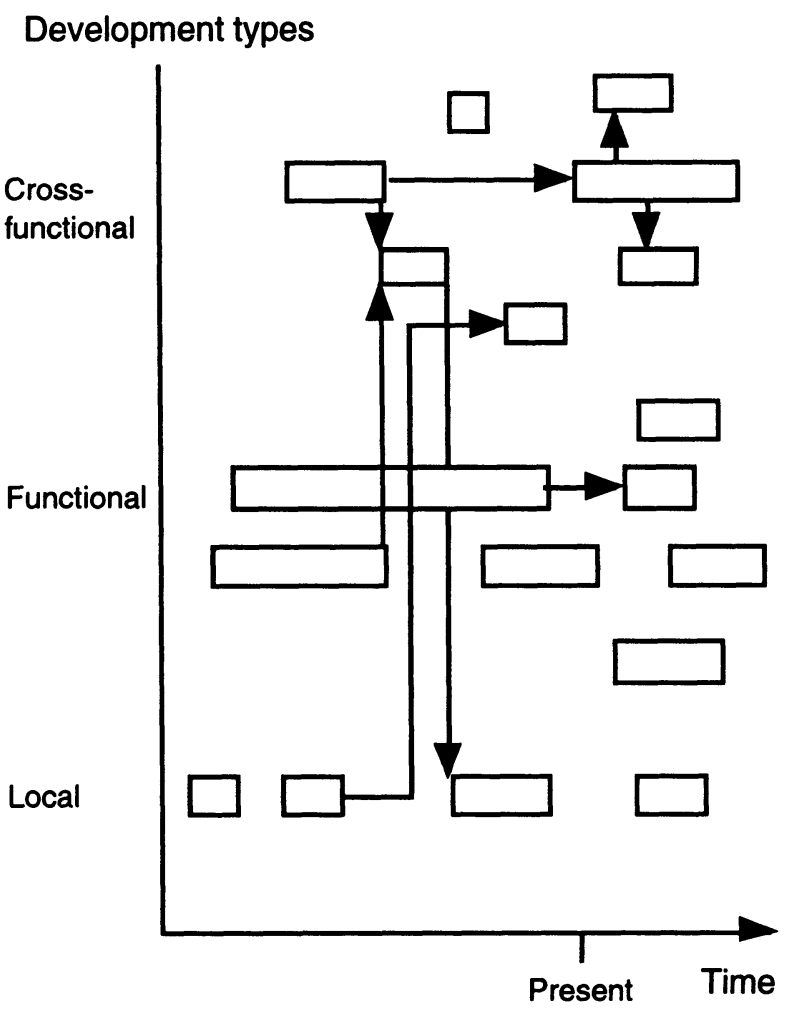

Figure 3 A mapping of 18 development projects in company $\mathrm{C}$

\section{RESULTS FROM A SURVEY ON CONTINUOUS IMPROVE- MENT}

A survey of 87 Danish industrial business units indicates that most of the companies have two to five years of experience with Continuous Improvement. The survey was conducted as part of a EUREKA network activity called EuroCINet (Gertsen et al., 1995) and may be slightly biased towards including several "Best in Class" companies in terms of engagement and application of Continuous Improvement.

To explore how experienced business units in the sample differ from less experienced business units, the sample was segmented into two groups according to the managers' own assessment of their status. The two groups comprise respectively $45 \%$ and $35 \%$ of the sample.

Some of the results of analyzing the two groups may be related to the three different types of development. The high experienced business units seem to 
consider Continuous Improvement as more strategically important and concerned with customer demands, i.e. cross-functional development. Continuous Improvement also seems to be more in line with previous change programs, and the business units are better to maintain the change process and to handle multiple development activities of different types.

Regarding functional and local development, in the high experienced business units almost all organizational levels contribute to the development activities.

If we narrow the group of experienced business units in our analysis by taking into consideration the number of years that they have been working with Continuous Improvement, the above tendencies appear stronger.

\section{DISCUSSION AND CONCLUSION}

Although only a few case examples have been used, it seems fair to claim that it is possible to depict the development process as a set of parallel and serial activities related to either of the three types of development. Some times it is necessary to split a project into sub-projects which belong to either of the three types of development. However, this calls for further studies of the interrelationships between development initiatives.

In the case studies it was observed that it was rather easy to identify an incremental development activity, whereas an innovative development project was difficult to describe. As a consequence, a more differentiated classification was offered and will be used in further studies. The case studies have supported the view that incremental and innovative changes are mutually interdependent.

The case studies clearly have demonstrated a need for mapping development activities of various kind as a means for providing a better overview of initiatives and utilization of their mutual interdependencies so as to achieve a potential synergy. Apparently, there are several obstacles in an industrial enterprise to achieve a better orchestration of development activities, such as decoupled initialization of change; the cost of coordination; incompatible mind set and terminology; communication problems; spatial separation of business units and sections; potential conflicts of interest; and competition on resources for various purposes. It is believed that a visual mapping of development activities may contribute to reduce some of these obstacles.

Introduction of new methods and systems in production management usually implies working with all three development types in parallel and sequentially. However, there is not one best entry for initiating a development process; it may either be as a local, a functional or a cross-functional development activity. We believe that an increased marginal overall improvement may often be achieved by shifting to another type of development. As a consequence, it is relevant to develop a capability for orchestrating improvement activities of different types. 


\section{REFERENCES}

Bessant, John et al. (1995): Continuous Improvement - The European Dimension. The 2nd International Conference on Management and New Production Systems. EurOMA. Twente 28-31 May, Netherlands.

Gertsen, Frank, Jeanette Knopp and Jens O. Riis (1995): Continuous Improvement in Danish Manufacturing Industries - Report from a survey of 87 business units. In Proceedings of the EuroCINet Conference, 6-7 December, Gatwick, UK.

Imai, Masaaki (1986): Kaizen, McGraw-Hill.

Riis, Jens O. (1990): The use of production management concepts in the design of production management systems, Production Planning $\mathcal{E}$ Control, Vol. 1, No. 1, 45-52.

Suzaki, Kiyoshi (1993): The New Shop Floor Management - Empowering People for Continuous Improvement, The Free Press.

\section{BIOGRAPHY}

Jens O. Riis is a Professor of Industrial Management Systems at the Department of Production, Aalborg University, Denmark. He holds an M.Sc. in Mechanical Engineering from the Technical University of Denmark and a Ph.D. in Operations Research from the University of Pennsylvania, USA. His main teaching and research areas are design of production management systems, technology management, project management, and integrated production systems. Prof. Riis is currently heading two research programs in integrated production systems and technology management, and is a member of the IFIP Working Group 5.7 on Computer Aided Production Management Systems and of the international editorial board of several international journals.

Jeanette Knopp received a B.Sc. in production engineering in 1991 from the Odense Technical College and an M.Sc. in industrial management systems from the Department of Production, Aalborg University in 1994. She is currently finishing her Ph.D. studies at the same department on Change Management. 